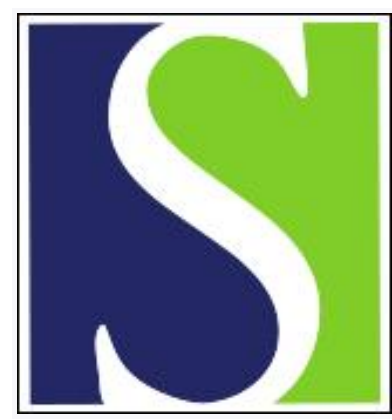

Scand J Work Environ Health 2012;38(5):456-466

https://doi.org/10.5271/sjweh.3287

Published online: 02 Mar 2012, Issue date: 01 Sep 2012

Trajectories and predictors of return to work after traumatic limb injury - a 2-year follow-up study

by Hou W-H, Sheu C-F, Liang H-W, Hsieh C-L, Lee Y, Chuang H-Y, Cheng Y-T

Affiliation: Department of Public Health, College of Health Sciences, Kaohsiung Medical University, 100, Shih-Chuan 1st Road, Kaohsiung City, 80708, Taiwan. hychuang@gmail.com

Refers to the following texts of the Journal: $2011 ; 37(6): 455-463$ 2010;36(6):473-483

The following articles refer to this text: $2012 ; 38(6): 485-488$; 2017;43(1):42-49

Key terms: disability; follow-up study; health; health; international classification of functioning; limb injury; predictor; return to work; Taiwan; vocational rehabilitation

This article in PubMed: www.ncbi.nlm.nih.gov/pubmed/22388635 


\title{
Trajectories and predictors of return to work after traumatic limb injury - a 2-year follow-up study
}

\author{
by Wen-Hsuan Hou, MD, MSc, ${ }^{1,2}$ Ching-Fan Sheu, PhD, ${ }^{3}$ Huey-Wen Liang, MD, PhD, ${ }^{4}$ Ching-Lin Hsieh, \\ PhD, ${ }^{5}$ Yen Lee, MSc, ${ }^{6}$ Hung-Yi Chuang, MD, MPH, ScD, ${ }^{1,7}$ Yan-Tzong Cheng, MSc ${ }^{8}$
}

\begin{abstract}
Hou W-H, Sheu C-F, Liang H-W, Hsieh C-L, Lee Y, Chuang H-Y, Cheng Y-T. Trajectories and predictors of return to work after traumatic limb injury - a 2-year follow-up study. Scand J Work Environ Health. 2012;38(5):456-466. doi:10.5271/sjweh.3287
\end{abstract}

Objectives This study aims to explore the trajectories of return to work (RTW) and examine the predictors of different trajectories among workers following traumatic limb injury.

Methods A total of 804 participants were recruited during hospital admission for a 2-year prospective study. The RTW outcome was repeatedly assessed at 1, 3, 6, 12, 18, and 24 months after the injury. A group-based trajectory model (GBTM) was employed to identify trajectories of RTW among the participants. Comparisons of group characteristics of different trajectories were performed based on a multinomial logistic regression.

Results GBTM identified three distinct trajectories of RTW: (i) fast RTW consisted of workers with early and stable RTW status from the first month after the injury; (ii) average RTW consisted of workers who achieved and remained at a stable RTW status within 6 months; and (iii) slow RTW consisted of workers who had slow and unsustainable RTW status within the 2-year follow-up period. The estimated proportions were $21.5 \%, 50.7 \%$, and $27.8 \%$, respectively. Workers with slow and unsustainable RTW after injury were found to be older, married, less educated, employed as repair personnel/operators/laborers, seriously injured, and depressed; they were also found to feel more disturbance in daily life, have lower self-efficacy, and believe they experience a poorer quality of life.

Conclusion Following traumatic limb injury, individual workers showed three distinct RTW trajectories, each of which was associated with different categories of biopsychosocial factors. An understanding of how different factors contribute to increasing the likelihood of RTW for injured workers in each trajectory group should aid policy-making in worker-oriented vocational rehabilitation programs.

Key terms disability; health; international classification of functioning; Taiwan; vocational rehabilitation.

Traumatic limb injury is a leading cause of work disability (1). The upper and lower extremities are the most commonly injured sites in motor vehicle accidents and occupational accidents (2-4). In the US, the number of lost working days associated with these injuries is estimated to be about 60 million, and lost productivity is estimated to cost over $\$ 7.5$ billion annually (2). After returning to their former jobs, however, many survivors of severe injuries are able to achieve a quality of life
(QOL) comparable with the normal population (5). Given that return to work (RTW) is one of the major goals for rehabilitating injured workers, it is important to identify early prognostic factors associated with a greater risk of no RTW in order to reduce the personal, social, and financial burden of traumatic limb injury.

Because an orthopedic injury causes not only bodily functional impairment but also limitations in daily activities and social participation related to the impairment,

1 Department of Public Health, College of Health Sciences, Kaohsiung Medical University, Kaohsiung, Taiwan.

2 Department of Physical Medicine and Rehabilitation, E-DA Hospital and I-Shou University, Kaohsiung, Taiwan.

3 Institute of Education, College of Social Science, National Cheng Kung University, Tainan, Taiwan.

4 Department of Physical Medicine \& Rehabilitation, National Taiwan University Hospital and National Taiwan University College of Medicine, Taipei, Taiwan.

5 School of Occupational Therapy, College of Medicine, National Taiwan University, Taipei, Taiwan.

6 Department of Psychology, College of Social Science, National Cheng Kung University, Tainan, Taiwan.

7 Department of Occupational and Environmental Medicine, Kaohsiung Medical University Hospital, Kaohsiung, Taiwan.

8 Marketing and Planning Department, Jauan Community Health Care Union, Chiayi, Taiwan.

Correspondence to: Hung-Yi Chuang, Department of Public Health, College of Health Sciences, Kaohsiung Medical University, and Department of Occupational and Environmental Medicine, Kaohsiung Medical University Hospital, 100, Shih-Chuan 1st Road, Kaohsiung City, 80708, Taiwan. [E-mail: hychuang@gmail.com] 
the International Classification of Functioning, Disability and Health (ICF) framework recognizes the complex interaction between its different components: body functions, body structures, activities and participation, environmental factors, and personal factors (6). It has been applied as a reference model in a longitudinal study of post-injury functioning after multiple injuries (7). A recent systematic review also adopted the ICF framework to examine the prognostic factors of RTW and concluded that younger patients with above average self-efficacy and not in receipt of injury compensation had a shorter duration of time off work following acute orthopedic injury to limbs (8).

To facilitate the likelihood of injured workers' RTW, risk factors that could delay or prevent such an outcome need to be identified. Previous studies have documented the complex nature of biopsychosocial factors associated with RTW outcome among workers with traumatic injuries using various statistical methods. In addition to the domains of body function, activity, participation, and personal factors of the ICF model, the likelihood of RTW is also dependent on societies and countries with different healthcare systems, work compensation legislation, employment status, etc. So far, very few studies have reported on the RTW condition following traumatic limb injury in non-Western countries (9).

Previous methods treated RTW outcome as a stable end-point and follow-up investigations were seldom conducted after the first occurrence of RTW. Such an approach is unrealistic in the labor market, for RTW might be a transitional status; in short, RTW can be temporary. The RTW outcome is not a permanent state after the first occurrence of RTW among injured workers. For example, many workers are unable to continue work after RTW due to a "secondary injury" or "work incapability" after their traumatic limb injury. A couple of previous studies recognized this aspect of RTW and reported changes of RTW status among workers based on follow-up observations up to five years after injury (10-11). The latest study also analyzed the predictors of RTW according to the RTW status at discharge and at one and two years after injury, respectively (10). However, it is necessary to treat the RTW status of workers in terms of a population that contains subgroups of different RTW trajectories for high-risk group identification and policy-making.

The aim of this study was to identify distinct RTW trajectories during two years of follow-up of traumatic limb injuries and to find predictors for distinguishing between trajectories. We also examined whether injury condition and physical, mental, activity, participation, personal, and environmental characteristics at baseline may predict the RTW trajectories after traumatic limb injury.

\section{Methods}

\section{Participants}

Patients diagnosed with limb injuries and hospitalized in the orthopedic and plastic surgery wards in a teaching hospital in Southern Taiwan were consecutively recruited for the study. Inclusion criteria were: 20-65 years of age and hospitalization within 14 days of injury. Those unable to read or answer the questionnaires, foreign workers, and those with coexisting injuries to the central nervous system (ie, traumatic brain injury or spinal cord injury) or internal organs were excluded. Consecutive cases were collected in the wards from January-December 2009 prospectively for 24 months. The ethics committee of the participating hospital approved the study; all participants gave their informed consent before taking part in the research.

\section{Procedure}

Participants answered a baseline questionnaire during hospitalization regarding personal data (age, gender, marital status, education level), environmental factor (insurance coverage), and occupational history (job titles and seniority). Medical charts were reviewed for the following information: diagnosis, injury dates, date of admission and discharge, and causes or mechanisms of injury. Each patient's injury history, self-efficacy of RTW, participation in daily life, QOL, and psychological symptoms were collected within two weeks of the injury. Two trained personnel conducted the follow-up survey of RTW status of all participants at 1, 3, 6, 12, 18 , and 24 months after the injury by telephone, mail, or face-to-face interview at out-patient clinics.

\section{Measures}

The following factors influencing RTW were examined in the current study. These factors cover all components of the ICF model.

Return to work. The RTW status was a dichotomous variable. It was recorded either as "without RTW" or "RTW". Three levels of self-report RTW status were collected by trained interviewers: (i) RTW in the same job and the same workplace; (ii) RTW in a different job but at the same workplace; (iii) RTW at a different workplace (12).

Occupations. There were four categories of occupations. "White-collar workers" included managers, professionals, technical personnel, salespersons, administrators, and service personnel. "Blue-collar workers" were divided into two classes: (i) workers in farming/forestry/ 
fishing industries and (ii) repairs personnel/machine operators/laborers (13). "Part-time job" referred to students or persons who worked fewer hours (usually $<35$ hours) per week than a full-time job (14). A previous study showed that these hierarchical job classes were associated with a significant trend in risks of adverse health outcomes, where "repair personnel/operators/ laborers" experienced the most elevated risk of adverse health outcomes (15).

Insurance system. Taiwan launched its National Health Insurance system in March 1995. This universal health program has covered $98.4 \%$ of the Taiwanese population since 2007 (16). The work compensation system in Taiwan is a national program that has insured 8.8-9.4 million workers (ie, $\sim 55-57 \%$ of the worker population) in the past 3 years (17). This system provides no-fault compensation and temporary partial income replacement if workers are unable to earn wages because of sick leave due to occupational injuries or disease (9). People can also purchase private health insurance to supplement the compensation for their injury episodes. Generalization of our study results should be limited to societies or countries with healthcare and compensation systems that are very similar to Taiwan's.

Injury energy, injury part, and the length of hospital stay. We classified injury energy into high- (eg, vehicular trauma or fall from height) or low-energy (eg, cutting, crashing, or crushing by the machines) categories. Previous studies specified that the high-energy category usually results in complicated destructive bony injury, while the low-energy category rarely does (18). The injury parts were grouped according to the presence of musculoskeletal involvement for "1 upper limb", "1 lower limb", " $\geq 2$ limbs", and "limb and other body parts". The length of hospital stay in days was retrieved from medical charts. All three measures have been validated in previous research as being significant determinants of RTW.

World Health Organization Quality of Life. The World Health Organization Quality of Life Assessment (WHOQOL-BREF) contains four domains of QOL: physical health, psychological health, social relationships, and environment (19). It shows good-to-excellent internal consistency, test-retest reliability, discriminate validity, and construct validity in the healthy population and different patient groups (20). We administered the WHOQOL-BREF to participants two weeks following their injury. This information reflects participants' QOL condition shortly after injury.

Depressive symptoms. The 5-item Brief Symptom Rating Scale (BSRS-5) measures the symptom items of anxiety, depression, hostility, interpersonal sensitivity/ inferiority, and insomnia (21). The self-report survey requires respondents to answer whether they have felt tense, blue, irritated, or inferior, or have had trouble falling asleep, which together reflect the personal factors of the ICF model. The responses of the BSRS-5 are rated on a 5 -point scale of $0-4$, with $0=$ not at all and $4=$ extremely $(22-23)$.

Self-efficacy of RTW. One question adapted to measure the self-efficacy of RTW was: "What is the likelihood of your returning to work within one month?" The respondents gave their estimates from 1 (no chance) to 5 (very high). Previous research has demonstrated that self-efficacy plays an important role in the RTW process, presumably because it is a consequence of the interplay of the employment situation, the medical care process, and the individual worker's health and personal characteristics (24). It is noted that self-efficacy is likely to be impacted by the physician's estimation of ability for employment or injury severity. We thought it belonged with the personal factor of the ICF model because it aims to get a broad and stable sense of personal competence to deal effectively with a variety of stressful situations (25).

Disturbance in participating in daily life. A 5-point categorical response to the question, "What has been the disturbance in participating in daily life after this injury?" was used to measure the disruption to daily life as a result of the injury. A higher score indicates more "disturbance in participating in daily life" (ie, more difficulties adjusting to normal day-to-day activities).

\section{Statistical analysis}

Group-based trajectory modeling (GBTM) is a recently developed statistical method to "identify distinctive features of the population distribution of trajectories" (26). The approach is particularly useful in discovering heterogeneous subpopulations. The technique has been applied to identify distinct work ability trajectories (27), but not for RTW. In this study, we used the Bayesian information criterion (BIC) to test from 1-6 trajectories and determine whether each trajectory was best fit by intercept only (ie, constant) or by linear, quadratic, or cubic terms (28-29). For each number of trajectories, the order of the equations was varied until a best-fitting model was derived with the use of the following formula: $2(\Delta \mathrm{BIC})>2(28)$. The best model was taken as the one with the smallest absolute value of the BIC (30). We used the following diagnostic criteria to check the adequacy of the model: (i) average posterior probability of assignment $>0.7$; (ii) odds of correct classification $>5$; and (iii) estimated group probabilities that did not deviate from the proportions 
of group assignments (26). The homogeneity of each identified trajectory was estimated based on $95 \%$ confidence intervals $(95 \% \mathrm{CI})$.

Furthermore, multiple multinomial logistic regressions were also performed to test whether the baseline variables may predict the group allocation (26, $31)$. The likelihood ratio $\chi^{2}$ statistic was used to test model fitness, and the $\tau$ statistic was used to identify any significant effect of the independent variables in predicting the group allocation during posterior comparisons. Since three RTW trajectories have been identified, one multinomial logistic regression equation model was used to predict an individual's probability of belonging to a particular trajectory group based on variables defined in the ICF framework. The potential predictors for every possible pair of RTW trajectory groups being compared were examined separately (32). In the multiple multinominal logistic regression models, a problem of collinearity could arise between covariates, producing unreliable estimated regression coefficients. To examine this issue, we assessed the sizes of regression coefficients and their standard errors (SE) obtained from separate individual simple regression models and those from the overall multiple regression model. We concluded that collinearity posed no serious concern to our data analysis strategy, as the multiple multinomial logistic model that included all baseline variables had estimated regression coefficients and estimated SE similar to those found with separate individual simple regressions (33). We used the SAS software, version 9.1.3 (SAS Institute, Cary NC, USA), PROC Traj macro (28-29) for the GBTM, data imputations, and multiple multinomial logistic regression modeling. The level of statistical significance was set at 0.05 (two-sided) (34).

\section{Results}

The characteristics of the 804 injured workers [574 males and 230 females, with an average age of 42 (standard deviation [SD] 14.8) years] recruited 14 days after traumatic limb injury are reported in table 1 . Over half of the workers were blue-collar, married, and insured with both labor and private compensation, and suffered "high-energy" injuries. The average period of hospitalization was eight days.

\section{RTW trajectories}

We estimated the group trajectories of the RTW condition using single-, two-, three-, four-, five-, and sixgroup models without including covariates. The smallest BIC scores (in absolute value) for the significant models are shown in table 2: -2116.6 (single-group model), -1588.5 (two-group model), -1583.7 (threegroup model), -1551.2 (four-group model), -1594.4 (five-group model), and -1564.1 (six-group model). Although the four-group model had the smallest BIC score (in absolute values), the SE of the estimates are not stably separable by statistical criteria among different combinations with the polynomial function of time (up to a third-order polynomial). Therefore, we selected the three-group model, consisting of the cubic, quadratic, and intercept equation (BIC score -1583.7), as the bestfitting model. In addition, the average posterior probability ranged from $0.89-0.93$, and the odds of correct classification ranged from 13.0-32.2, which suggested that the individual trajectories matched the empirically determined groups.

The participants were assigned to different trajectories according to the highest posterior probability of membership in each trajectory class. Figure 1 illustrates the three trajectory-based categories of traumatic limb injuries: (i) fast RTW (21.5\% probability), who maintained a quick and stable RTW status from the first month follow-up after injury; (ii) average RTW (50.7\% probability), who achieved RTW status within 6 months of their injury; and (iii) slow RTW (27.8\% probability), who experienced a slow and unsustainable RTW status during the 2-year follow-up period after injury ( $>50 \%$ of this group did not return to work steadily). Of the 804 participants, 228 made up the slow RTW group, 399 fell into the average RTW group, and the remaining 177 comprised the fast RTW group. For each trajectory, the predicted values of RTW did not differ from the observed values. The results shown in figure $1 \mathrm{did}$ not change appreciably after adjustments for age, gender, and marital status.

\section{Comparing baseline characteristics across trajectories}

The characteristics of the traumatic limb injuries according to the RTW trajectory are shown in table 1. The mean age ranged from 38.1 years in the fast RTW group to 46.7 years in the group with slow RTW. The hospitalization days also followed a decreasing pattern from slow to average to fast RTW groups (11.3, 7.3, 5.4 days, respectively). Men and high-energy injuries were overrepresented in all three groups; especially the fast RTW group consisted mostly of men $(76.3 \%)$ and the slow RTW group consisted mostly of high-energy injuries $(83.3 \%)$. As for the obtainment of insurance compensation for the injury, only modest differences were found across the three groups. There were significant differences in the educational level, occupation titles, parts injured, disturbance in daily life, and self-efficacy of RTW in one month across the three groups. The slow RTW 
Table 1. Baseline characteristics per return-to-work (RTW) trajectory. [BSRS-5=5-item Brief Symptom Rating Scale; SD=standard deviation; WHOQOL-BREF=World Health Organization Quality of Life Assessment]

\begin{tabular}{|c|c|c|c|c|c|c|c|c|c|c|c|c|c|c|c|c|}
\hline \multirow[t]{2}{*}{ Trajectory } & \multicolumn{4}{|c|}{ Slow RTW (N=228) } & \multicolumn{4}{|c|}{ Average RTW (N=399) } & \multicolumn{4}{|c|}{ Fast RTW (N=177) } & \multicolumn{4}{|c|}{ Total $(\mathrm{N}=804)$} \\
\hline & $\mathrm{N}$ & $\%$ & Mean & SD & $\mathrm{N}$ & $\%$ & Mean & $\overline{S D}$ & $\mathrm{~N}$ & $\%$ & Mean & SD & $\mathrm{N}$ & $\%$ & Mean & SD \\
\hline Age & & & 46.7 & 15.6 & & & 40.7 & 14.5 & & & 38.1 & 14.8 & & & 41.8 & 15.2 \\
\hline \multicolumn{17}{|l|}{ Gender } \\
\hline Male & 158 & 69.3 & & & 281 & 70.4 & & & 135 & 76.3 & & & 574 & 71.4 & & \\
\hline Female & 70 & 30.7 & & & 118 & 29.6 & & & 42 & 23.7 & & & 230 & 28.6 & & \\
\hline \multicolumn{17}{|l|}{ Marital status } \\
\hline Married & 140 & 61.4 & & & 237 & 59.4 & & & 102 & 57.6 & & & 479 & 59.6 & & \\
\hline Single, divorced or widowed & 88 & 38.6 & & & 162 & 40.6 & & & 75 & 42.4 & & & 325 & 40.4 & & \\
\hline \multicolumn{17}{|l|}{ Education years a } \\
\hline$<9$ & 132 & 57.9 & & & 138 & 34.6 & & & 46 & 26.0 & & & 316 & 39.3 & & \\
\hline $9 \sim 12$ & 74 & 32.5 & & & 176 & 44.1 & & & 72 & 40.7 & & & 322 & 40.0 & & \\
\hline$>12$ & 22 & 9.6 & & & 85 & 21.3 & & & 59 & 33.3 & & & 166 & 20.6 & & \\
\hline \multicolumn{17}{|l|}{ Injury energy } \\
\hline High energy & 190 & 83.3 & & & 311 & 77.9 & & & 132 & 74.6 & & & 633 & 78.7 & & \\
\hline Low energy & 38 & 16.7 & & & 88 & 22.1 & & & 45 & 25.4 & & & 171 & 21.3 & & \\
\hline Length of hospital stay (days) a & & & 11.3 & 9.9 & & & 7.3 & 6.4 & & & 5.4 & 3.4 & & & 8.0 & 7.4 \\
\hline \multicolumn{17}{|l|}{ Insurance system a } \\
\hline National Health Insurance & 21 & 9.2 & & & 27 & 6.8 & & & 5 & 2.8 & & & 53 & 6.6 & & \\
\hline Work compensation & 59 & 25.9 & & & 84 & 21.1 & & & 28 & 15.8 & & & 171 & 21.3 & & \\
\hline Private health insurance & 44 & 19.3 & & & 69 & 17.3 & & & 30 & 16.9 & & & 143 & 17.8 & & \\
\hline Combined all three insurance & 104 & 45.6 & & & 219 & 54.9 & & & 114 & 64.4 & & & 437 & 54.4 & & \\
\hline \multicolumn{17}{|l|}{ Occupation a } \\
\hline White-collar full time & 30 & 13.2 & & & 84 & 21.1 & & & 61 & 34.5 & & & 175 & 21.8 & & \\
\hline Workers in farming/forestry/fishing & 101 & 44.3 & & & 152 & 38.1 & & & 60 & 33.9 & & & 313 & 38.9 & & \\
\hline Repair personnel/operators/laborers & 73 & 32.0 & & & 134 & 33.6 & & & 39 & 22.0 & & & 246 & 30.6 & & \\
\hline Part time job & 24 & 10.5 & & & 29 & 7.3 & & & 17 & 9.6 & & & 70 & 8.7 & & \\
\hline \multicolumn{17}{|l|}{ Injury part a } \\
\hline 1 upper limb & 51 & 22.4 & & & 187 & 46.9 & & & 86 & 48.6 & & & 324 & 40.3 & & \\
\hline 1 lower limb & 98 & 43.0 & & & 119 & 29.8 & & & 36 & 20.3 & & & 253 & 31.5 & & \\
\hline$\geq 2$ limbs & 36 & 15.8 & & & 38 & 9.5 & & & 8 & 4.5 & & & 82 & 10.2 & & \\
\hline Limb and other body parts & 43 & 18.9 & & & 55 & 13.8 & & & 47 & 26.6 & & & 145 & 18.0 & & \\
\hline \multicolumn{17}{|l|}{ Self-efficacy of RTW in one month a } \\
\hline No chance & 143 & 62.7 & & & 177 & 44.4 & & & 53 & 29.9 & & & 373 & 46.4 & & \\
\hline Moderate chance & 70 & 30.7 & & & 164 & 41.1 & & & 86 & 48.6 & & & 320 & 39.8 & & \\
\hline High chance & 15 & 6.6 & & & 58 & 14.5 & & & 38 & 21.5 & & & 111 & 13.8 & & \\
\hline \multicolumn{17}{|l|}{ Disturbance in daily life a } \\
\hline Mild & 98 & 43.0 & & & 45 & 11.3 & & & 65 & 36.7 & & & 139 & 17.3 & & \\
\hline Moderate & 33 & 14.5 & & & 73 & 18.3 & & & 34 & 19.2 & & & 140 & 17.4 & & \\
\hline Severe & 170 & 74.6 & & & 259 & 64.9 & & & 96 & 54.2 & & & 525 & 65.3 & & \\
\hline \multicolumn{17}{|l|}{ WHOQOL-BREF (range) } \\
\hline Physical (4-20) & & & 13.0 & 2.0 & & & 13.8 & 1.9 & & & 14.0 & 1.7 & & & 13.6 & 1.9 \\
\hline Psychological (4-20) & & & 12.7 & 2.3 & & & 13.3 & 2.3 & & & 13.2 & 2.2 & & & 13.1 & 2.3 \\
\hline Social (4-20) & & & 14.2 & 2.1 & & & 14.5 & 2.1 & & & 14.5 & 2.0 & & & 14.4 & 2.1 \\
\hline Environmental (4-20) & & & 13.4 & 1.9 & & & 13.9 & 1.9 & & & 13.9 & 2.0 & & & 13.8 & 1.9 \\
\hline BSRS-5 (0-20) & & & 3.7 & 3.9 & & & 2.8 & 3.2 & & & 2.5 & 3.1 & & & 3.0 & 3.4 \\
\hline
\end{tabular}

a $P$-value $<0.001$

group comprised the greatest proportion of the following categories: (i) lowest educational level, (ii) blue-collar, (iii) 1 lower limb involvement, (iv) severe disturbance in daily life, and (v) no self-confidence of returning to work in one month. In addition, the BSRS scores revealed a decreasing trend of 3.7, 2.8, and 2.5 points from the slow to average to fast RTW groups. However, no obvious significances were detected among the physical, psychological, social, and environmental domains of the WHOQOL-BREF.

\section{Predictors of different RTW trajectories}

Table 3 shows the multinomial logistic regression models for the comparison of the baseline characteristics among the three groups. Comparing the slow and fast RTW groups, the slow RTW group was significantly more likely to comprise individuals who: (i) were older [adjusted odds ratio $\left(\mathrm{OR}_{\mathrm{adj}}\right) 1.04,95 \%$ CI 1.01-1.06], (ii) had longer hospitalization stays $\left(\mathrm{OR}_{\mathrm{adj}} 1.18,95 \% \mathrm{CI}\right.$ 1.11-1.25), (iii) worked in farming/forestry/fishing or 
Table 2. Bayesian Information Criterion (BIC) and 2 loge(B10). Note: Although the four-group model had the smallest BIC score (in absolute values), the standard errors of the estimates are not stably separable by statistical criteria among different combinations with the polynomial function of time (up to a third-order polynomial). Therefore, we selected the three-group model, consisting of the cubic, quadratic, and intercept equation (BIC score -1583.7) as the best-fitting model.

\begin{tabular}{lccr}
\hline $\begin{array}{l}\text { Number of } \\
\text { groups }\end{array}$ & BIC & Null model & 2 loge(B10) \\
\hline 1 & -2116.6 & & \\
2 & -1588.8 & 1 & 1055.6 \\
3 & -1583.7 & 2 & 10.2 \\
4 & -1551.2 & 3 & 65 \\
5 & -1594.4 & 4 & -86.4 \\
6 & -1564.1 & 5 & 60.6 \\
\hline
\end{tabular}

repair personnel/operators/laborers, or held part-time jobs $\left(\mathrm{OR}_{\text {adj }} 2.24 \sim 3.24,95 \%\right.$ CI 1.09 1.59-4.48 7.00), (iv) had 1 lower or $>2$ limbs injured $\left(\mathrm{OR}_{\mathrm{adj}} 3.63\right.$ versus 4.22 , 95\% CI 2.00-6.60 versus 1.59-11.20, respectively), (v) had moderate or severe disturbance in daily life $\left(\mathrm{OR}_{\mathrm{adj}}\right.$ 2.34 versus $2.10,95 \%$ CI $1.02-5.40$ versus $1.02-4.30$ respectively), (vi) had higher psychological scores on the WHOQOL-BREF (OR adj $1.22,95 \%$ CI 1.04-1.41), and (vii) scored higher on the BSRS-5 $\left(\mathrm{OR}_{\mathrm{adj}} 1.11,95 \% \mathrm{CI}\right.$ 1.03-1.20). Whereas those who (i) were married $\left(\mathrm{OR}_{\mathrm{adj}}\right.$ $0.50,95 \%$ CI $0.27-0.93$ ), (ii) had a high educational level of $>12$ years $\left(\mathrm{OR}_{\text {adj }} 0.21,95 \%\right.$ CI $\left.0.09-0.50\right)$, and (iii) had moderate or high self-efficacy of RTW $\left(\mathrm{OR}_{\mathrm{adj}} 0.29\right.$ versus $0.20,95 \%$ CI $0.17-0.51$ versus $0.09-0.47$ respectively) were more likely to be in the fast RTW group.

Comparing the average and fast RTW groups, the average RTW group was significantly more likely to comprise individuals: (i) with longer hospitalization stays $\left(\mathrm{OR}_{\text {adj }} 1.11,95 \%\right.$ CI 1.05-1.18), (ii) who obtained work or private insurance for the injury $\left(\mathrm{OR}_{\text {adj }} 1.18,95 \%\right.$ CI 1.11-1.25), (iii) who worked in farming/forestry/fishing or were repair personnel/operators/laborers $\left(\mathrm{OR}_{\mathrm{ad}}\right.$ 1.94 versus $2.73,95 \%$ CI $0.14-3.35$ versus $1.57-4.74$ ), and (iv) who had higher psychological scores on the WHOQOL-BREF (OR adj $1.15,95 \%$ CI 1.01-1.30). Whereas those who suffered from injuries to limbs and other body parts $\left(\mathrm{OR}_{\mathrm{adj}} 0.46,95 \%\right.$ CI $\left.0.28-0.78\right)$ and had high self-efficacy of RTW in one month $\left(\mathrm{OR}_{\mathrm{ad}}\right.$ $0.60,95 \%$ CI $0.33-1.09$ ) were more likely to be in the fast RTW group.

Comparing the slow and average RTW groups, the slow RTW group was significantly more likely to comprise individuals who: (i) were older $\left(\mathrm{OR}_{\text {adj }} 1.02\right.$, 95\% CI 1.00-1.04), (ii) had longer hospitalization stays $\left(\mathrm{OR}_{\text {adj }} 1.06,95 \%\right.$ CI $\left.1.03-1.08\right)$, and (iii) had injuries to 1 lower, $\geq 2$ limbs, or limb and other body parts $\left(\mathrm{OR}_{\text {adj }} 2.39 \sim 2.52,95 \%\right.$ CI 1.32 1.61-3.95 4.54). Whereas those who (i) were married $\left(\mathrm{OR}_{\mathrm{adj}} 0.63,95 \%\right.$ CI 0.40-1.00), (ii) had a higher educational level of 9-12 or $>12$ years $\left(\mathrm{OR}_{\text {adj }} 0.53\right.$ versus $0.32,95 \% \mathrm{CI}$

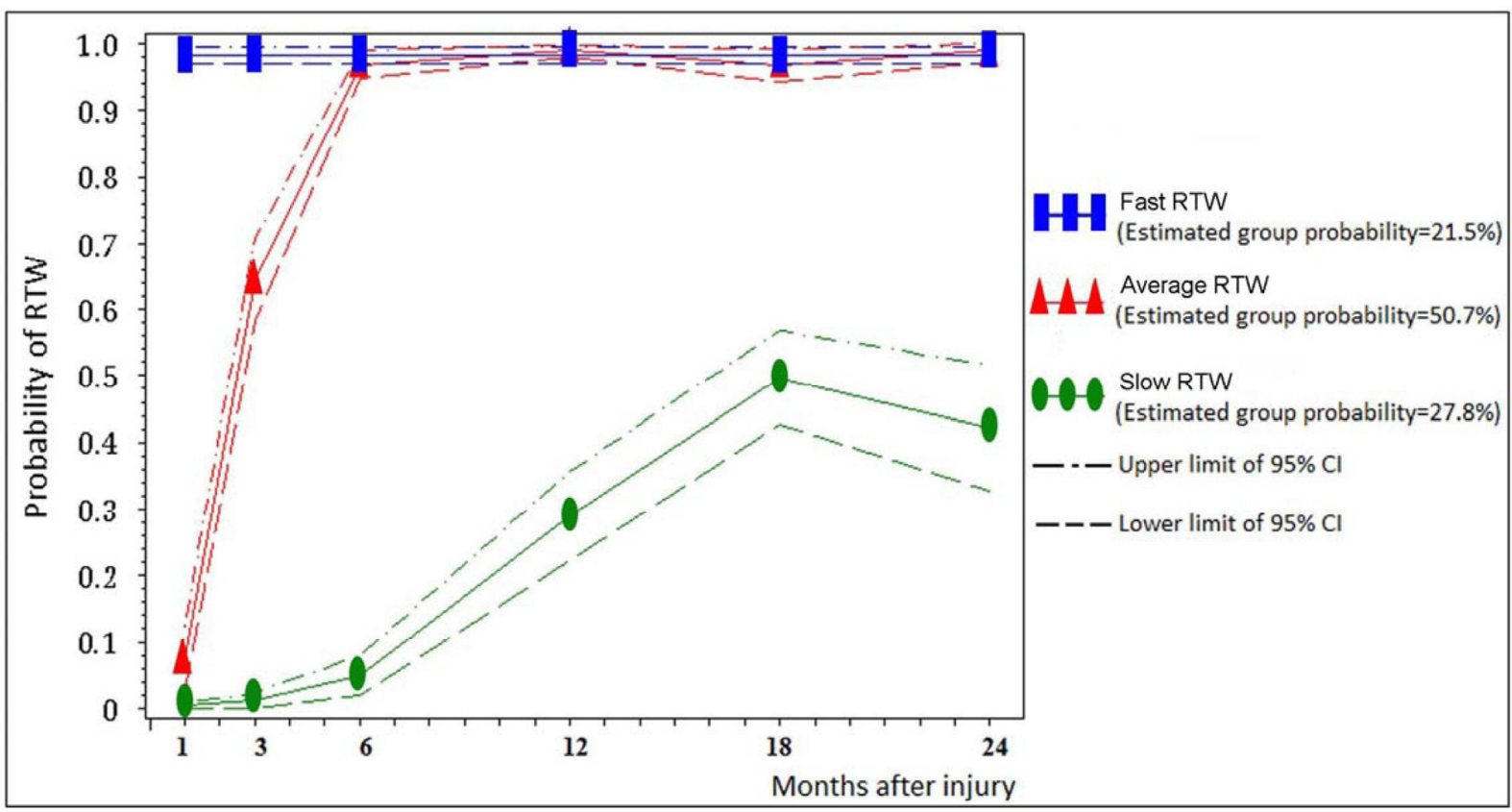

Figure 1. Trajectories and confidence intervals of return to work (RTW) among workers with traumatic limb injuries ( $\mathrm{N}=804)$. [95\% $\mathrm{Cl}=95 \%$ confidence interval] 
Table 3. Adjusted odds ratio (OR) of trajectory group allocation in relation to baseline variables. [RTW=return to work; $95 \% \mathrm{Cl}=95 \%$ confidence interval; WHO-QOL-BREF=World Health Organization Quality of Life Assessment; BSRS-5=5-item Brief Symptom Rating Scale; $\mathrm{SD}=$ standard deviation]

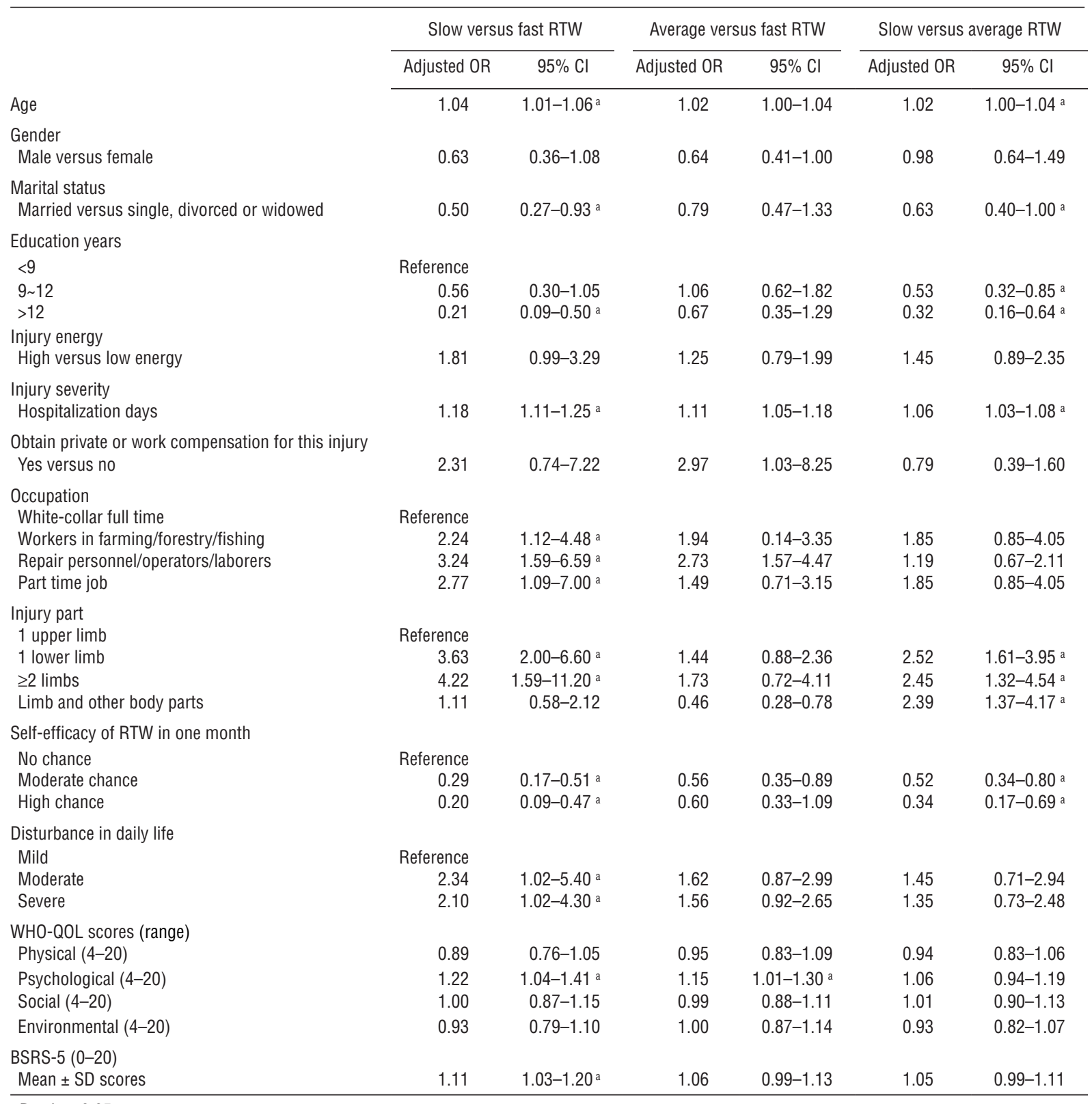

a $P$-value $<0.05$.

$0.32-0.85$ versus $0.16-0.64$ ), and (iii) had moderate or high self-efficacy of RTW ( $\mathrm{OR}_{\text {adj }} 0.52$ versus 0.34 , $95 \%$ CI $0.34-0.80$ versus $0.17-0.69$, respectively) were more likely to be in the average RTW group. For example, the coefficients for the marital status in the model can be interpreted as follows: holding the effects of all other terms in the model constant, a married subject - compared with a single (or divorced) subject - was 1.65 times more likely to belong to the fast RTW group in reference to the slow RTW, and 1.88 times more likely to belong to the average RTW group in reference to the slow RTW. This subject would be equally likely to belong to the average RTW group in reference to the fast RTW group. However, gender and three domains of the WHOQOL-BREF (ie, physical, social, and environmental) did not have a significant impact on the RTW trajectory of the traumatic limb injury, after adjustment for other confounding variables. That is to say, these characteristics did not predict the trajectory classification (table 3 ). 


\section{Discussion}

To the best of our knowledge, this is the first study to use GBTM to explore the RTW trajectory and to determine the relevant predictors within an ICF framework. We identified three distinct RTW trajectory classes of workers with traumatic limb injuries: slow RTW (27.8\% probability), average RTW (50.7\% probability), and fast RTW (21.5\% probability), and found that the distribution of these trajectories was quite varied. The latter two achieved $>85 \%$ RTW six months after injury.

Further comparing our study with previous studies, our GBTM findings supported the predictors (eg, age, gender, educational level, injury severity, self-efficacy, and QOL) of RTW reported in previous studies (8-9, 35-41). Patients found to be less likely to return to work were those who were older, less educated, and suffered from injury to one lower limb, or were seriously injured, had less self-efficacy, felt more disturbance in daily life, had worse QOL, and had poorer mental health. These predictors combined to account for about $34.8 \%$ of the total variance in our data under the explanatory model of the ICF framework.

One of the advantages of GBTM is that it can treat RTW as an outcome that changes over time. Workers often move in and out of an RTW status after traumatic limb injury because they have rehabilitated well or suffered from "secondary injury" or "work incapability" after their RTW. A previous study that treated RTW as a time-stable status found that the first occurrence of RTW after an injury marked a return to stable employment for $<40 \%$ of the workers who returned (42). The GBTM provides a novel statistical method to explore the dynamic trajectory patterns among latent subgroups from long-term repeated measurements. Previous RTW studies employed either the logistic regression or Cox's proportional hazards model to analyze work status as defined by the end-point of RTW $(9,36,39)$. These statistical models also assume a homogenous population of subjects as regards the RTW status, which might be realistic for a single terminal observation but unrealistic for consecutive observations of the same events. While reaching similar conclusions to those obtained by such statistical modeling, the GBTM is different in its ability to take into account the dynamic changes of RTW status, which showed distinct patterns among the study subjects (10-11). Several studies have adapted GBTM for longterm analysis of work ability trajectories (27), back injury trajectories (43), geriatric disability trajectories (34), and others. Since neither investigation of predictors nor comparison between RTW patterns has been evaluated, the GBTM provides a resolution to explore the time-dependent RTW status after workers' injuries in longitudinal follow-up.
Another advantage of using GBTM is that it allows the exploration of different distinct RTW trajectory patterns among the diverse population of traumatic limb injuries. Since the inconsistent results of the factors influencing RTW and the time of RTW after injury vary according to the wide range of injury conditions (4, 36-39, 44), we examined the injuries according to each trajectory of RTW and classified them by similar patterns (26). A 5-year study has explored the fact that although nearly half of the workers achieved complete RTW, the RTW process was not necessarily a continuous one, and could be disrupted by the need for sick leave benefits or vocational rehabilitation (10). Therefore, we chose GBTM, a model for individual-level heterogeneity in data, to identify groups with similar patterns over time, as opposed to the traditional regression analyses, which model only one mean within a sample (45). As such, the trajectory analyses facilitated the identification and definition of distinct subgroups and parameters for designing future etiologic epidemiological studies of the distinct RTW trajectories after traumatic limb injuries. Nevertheless, the application of the GBTM to identify or predict an individual patient's RTW trajectory may be clinically premature without a large-scale longitudinal study involving a comprehensive design including all potential within- and between-individual factors that could affect the trajectories for the patients. The reality of the influence of ever-changing dynamics between individual and environmental factors on the time course of an individual's RTW status would certainly require further sophisticated statistical modeling techniques to be developed. To increase the likelihood of injured workers' RTW, risk factors that could delay or prevent such an outcome need to be identified using various statistical methods such as structure equation modeling (46), multiple linear regression $(7,37)$, logistic regression (10-11), and Cox regression (9, 36, 38-39).

In this study, many predictors of RTW [ie, gender (9), age (38), marriage (47), educational level $(8,36$, 38-39), injury severity $(39,44,48)$, occupation $(8,36)$, work compensation (8), QOL $(46,49)$, depression (46), self-efficacy $(8,36)$, and participation in activities (47)] were identified, as in previous studies. Furthermore, we proposed the ICF scheme to conceptualize the interpretation of the multidimensional factors of RTW and the multidisciplinary interventions of vocational rehabilitation (50-51); however, no empirical data had been confirmed under the ICF framework. In addition, Taiwan has legislated the application of the ICF framework for sickness certificates in order to capture the intricate predictors of RTW, as in a recent study from Sweden (52). Therefore, construction of RTW predictors under the ICF framework is a practical and comprehensive resolution.

We have identified three limitations of the current study. First, due to the complex nature of the 
biopsychosocial factors of RTW, we could not be sufficiently comprehensive, despite efforts to include the major predictors with the ICF framework $\left(\mathrm{R}^{2}=0.33\right.$ by multinomial logistic regression). It is expected that many complex socio-environmental factors, such as healthcare system, work compensation legislation, and unemployment status, should and can have an impact on the likelihood of RTW status of an individual participant. Likewise, so do certain occupational factors such as job seniority, staff numbers, and job contents. Our study design focused largely on individual characteristics and included little information on either environmental or occupational factors in addressing the potential impacts of these factors on RTW. A more ambitious study including these multilevel social, environmental, and occupational factors could perhaps resolve some of the residual confounding issues in determining independent risk factors for RTW trajectory. That is to say, RTW depends on many factors, such as motivation, ability to adjust, occupation, health status, rehabilitation intervention, healthcare, social welfare, etc. The relationships between RTW and these factors are dynamic and vary greatly from one individual to another and across social strata. Statistical modeling is limited in its ability to explain such a complicated process.

Secondly, only $79.6 \%$ (a total of 3842 measures of RTW evaluation divided by 6 repeated follow-ups for each of 804 participants) were followed for the repeated measures of this study. However, we performed the posthoc analyses for the baseline demographics and found no significant differences between participants with and without loss of follow-up.

Finally, although the GBTM may have overcome the disadvantage of considering the first occurrence of RTW as a steady end-point in the traditional statistics (42), there were still two pitfalls of the RTW study. One is that RTW is never a homogeneous outcome composed of the outcomes of the same duties, modified tasks, or modified hours (12). The other problem is that further subgroup analysis (eg, injury parts, injury severity, occupation, etc) in a study with sufficient numbers of subjects in each subgroup could add useful information on the RTW among patients with traumatic limb injuries. Therefore, further detailed evaluation of the actual definition of RTW (eg, re-entry to work, full or parttime job, same tasks and/or hours, etc) with subgroup analysis is needed.

In conclusion, this study is an initial step toward understanding the trajectory and explaining the predictors of RTW within the ICF framework among workers with traumatic limb injuries. The results indicate that three distinct trajectory patterns of RTW exist with individuals' characteristic predictors. Therefore, it might be desirable for clinicians to monitor patients' RTW status for at least two years to identify the high-risk workers with different RTW trajectories to increase their likelihood of returning to work.

\section{Acknowledgement}

The authors would like to thank Pei-Shan Li and Jing-Wi Ni for document collection

This study was supported by research grants from the National Science Council (NSC 99-2314-B-650001-MY2) and the E-Da Hospital (EDAHP-98009 and EDAHP-99001).

\section{Previous presentation}

Part of this manuscript was presented in the Annual Conference of Taiwan Public Health Association, Taipei, Taiwan, 15 October 2011.

\section{References}

1. Ezzati M, Lopez AD, Rodgers A, Vander Hoorn S, Murray CJ. Selected major risk factors and global and regional burden of disease. Lancet. 2002;360:1347-60. http://dx.doi. org/10.1016/S0140-6736(02)11403-6.

2. Ebel BE, Mack C, Diehr P, Rivara FP. Lost working days, productivity, and restraint use among occupants of motor vehicles that crashed in the United States. Inj Prev. 2004;10:314-9. http://dx.doi.org/10.1136/ip.2004.005850.

3. Liu YH, Lin MR, Wang JD. Cost and determinants of morbidity from work related disabling injuries in Taiwan. Occup Environ Med. 1995;52:138-42. http://dx.doi. org/10.1136/oem.52.2.138.

4. Pransky GS, Benjamin KL, Savageau JA, Currivan D, Fletcher K. Outcomes in work-related injuries: a comparison of older and younger workers. Am J Ind Med. 2005;47:104-12. http://dx.doi.org/10.1002/ajim.20122.

5. Post RB, van der Sluis CK, Ten Duis HJ. Return to work and quality of life in severely injured patients. Disabil Rehabil. 2006;28:1399-404. http://dx.doi. org/10.1080/09638280600641392.

6. WHO. International Classification of Functioning, Disability and Health (ICF) 2001.

7. Soberg HL, Bautz-Holter E, Roise O, Finset A. Long-term multidimensional functional consequences of severe multiple injuries two years after trauma: a prospective longitudinal cohort study. J Trauma. 2007;62:461-70. http://dx.doi. org/10.1097/01.ta.0000222916.30253.ea.

8. Clay FJ, Newstead SV, McClure RJ. A systematic review of early prognostic factors for return to work following acute 
orthopaedic trauma. Injury. 2010;41:787-803. http://dx.doi. $\operatorname{org} / 10.1016 /$ j.injury.2010.04.005.

9. Hou WH, Tsauo JY, Lin CH, Liang HW, Du CL. Worker's compensation and return-to-work following orthopaedic injury to extremities. J Rehabil Med. 2008;40:440-5. http://dx.doi. org/10.2340/16501977-0194.

10. Soberg HL, Roise O, Bautz-Holter E, Finset A. Returning to work after severe multiple injuries: Multidimensional functioning and the trajectory from injury to work at 5 years. J Trauma. 2011;71:425-34. http://dx.doi.org/10.1097/ TA.0b013e3181eff54f.

11. Soberg HL, Finset A, Bautz-Holter E, Sandvik L, Roise O. Return to work after severe multiple injuries: a multidimensional approach on status 1 and 2 years postinjury. J Trauma. 2007;62:471-81. http://dx.doi.org/10.1097/ TA.0b013e31802e95f4.

12. Clay FJ, Newstead SV, D'Elia A, McClure RJ. First return to work following injury: does it reflect a composite or a homogeneous outcome? Occup Environ Med. 2010;67:730-6. http://dx.doi.org/10.1136/oem.2009.051797.

13. Classification of Occupation. Directorate-General of Budget, Accounting and Statistics, Executive Yuan, Taiwan; 2011 [updated May, 2010; cited 2011 22th, Feb]; Available from: http://www.dgbas.gov.tw/np.asp?ctNode=3371\&mp=1.

14. Feldman DC. Reconceptualizing the nature and consequences of part-time work. Acad Manage Rev. 1990;15:103-12.

15. Li CY, Wu SC, Sung FC. Lifetime principal occupation and risk of cognitive impairment among the elderly. Ind Health. 2002;40:7-13. http://dx.doi.org/10.2486/indhealth.40.7.

16. Lee MS, Hsu CC, Wahlqvist ML, Tsai HN, Chang YH, Huang YC. Type 2 diabetes increases and metformin reduces total, colorectal, liver and pancreatic cancer incidences in Taiwanese: a representative population prospective cohort study of 800,000 individuals. BMC Cancer. 2011;11:20. http:// dx.doi.org/10.1186/1471-2407-11-20.

17. Statistics of Labor. Council of Labor Affairs. Executive Yuan Taiwan; 2011 [cited 2011 20th, Sep]; Available from: http:/ statdb.cla.gov.tw/statis/stmain.jsp?sys=100.

18. Browner BD, Jupiter JB, Levine AM, Trafton PG. Chapter 58: Tibial Shaft Fractures. In: Trafton PG, editor. Skeletal trauma: basic science, management, and reconstruction. Orlando, FL: Saunders Company 2008. p. 2333-29.

19. Skevington SM, Lotfy M, O'Connell KA. The World Health Organization's WHOQOL-BREF quality of life assessment: psychometric properties and results of the international field trial. A report from the WHOQOL group. Qual Life Res. 2004;13:299-310. http://dx.doi.org/10.1023/ B:QURE.0000018486.91360.00.

20. Jang Y, Hsieh CL, Wang YH, Wu YH. A validity study of the WHOQOL-BREF assessment in persons with traumatic spinal cord injury. Arch Phys Med Rehabil. 2004;85:1890-5. http:// dx.doi.org/10.1016/j.apmr.2004.02.032.

21. Lung FW, Lee MB. The five-item Brief-Symptom Rating Scale as a suicide ideation screening instrument for psychiatric inpatients and community residents. BMC Psychiatry. 2008;8:53. http://dx.doi.org/10.1186/1471-244X-8-53.
22. Lee MB, Liao SC, Lee YJ, Wu CH, Tseng MC, Gau SF, et al. Development and verification of validity and reliability of a short screening instrument to identify psychiatric morbidity. J Formos Med Assoc. 2003;102:687-94.

23. Chen $\mathrm{HC}, \mathrm{Wu} \mathrm{CH}$, Lee YJ, Liao SC, Lee MB. Validity of the five-item Brief Symptom Rating Scale among subjects admitted for general health screening. J Formos Med Assoc. $2005 ; 104: 824-9$.

24. Labriola M, Lund T, Christensen KB, Albertsen K, Bultmann $\mathrm{U}$, Jensen JN, et al. Does self-efficacy predict return-to-work after sickness absence? A prospective study among 930 employees with sickness absence for three weeks or more. Work. 2007;29:233-8.

25. Schwarzer R, Bäßler J, Kwiatek P, Schröder K, Zhang JX. The Assessment of Optimistic Self-beliefs: Comparison of the German, Spanish, and Chinese Versions of the General Selfefficacy Scale. Appl Physiol Nur Me. 1997;46:69-88.

26. Nagin D. Group-based modeling of development: Cambridge, MA: Harvard University Press; 2005.

27. von Bonsdorff ME, Kokko K, Seitsamo J, von Bonsdorff MB, Nygard CH, Ilmarinen J, et al. Work strain in midlife and 28year work ability trajectories. Scand J Work Environ Health. 2011;37(6):455-63. http://dx.doi.org/10.5271/sjweh.3177.

28. Jones BL, Nagin DS, Roeder K. A SAS Procedure Based on Mixture Models for Estimating Developmental Trajectories. Social Method Res. 2001;29:374-93. http://dx.doi.org/10.11 77/0049124101029003005.

29. Jones BL, Nagin DS. Advances in Group-Based Trajectory Modeling and an SAS Procedure for Estimating Them. Social Method Res. 2007;35:542-71. http://dx.doi. org/10.1177/0049124106292364.

30. Schwarz G. Estimating the dimension of a model. Ann Stat. 1978;6:461-4. http://dx.doi.org/10.1214/aos/1176344136.

31. van Leeuwen CM, Post MW, Hoekstra T, van der Woude LH, de Groot S, Snoek GJ, et al. Trajectories in the course of life satisfaction after spinal cord injury: identification and predictors. Arch Phys Med Rehabil. 2011;92:207-13. http:// dx.doi.org/10.1016/j.apmr.2010.10.011.

32. Wong DC, Chan SS, Fong DY, Leung AY, Lam DO, Lam TH. Quitting trajectories of Chinese youth smokers following telephone smoking cessation counseling: a longitudinal study. Nicotine Tob Res. 2011;13:848-59. http://dx.doi. org/10.1093/ntr/ntr086.

33. Hosmer DW, Lemeshow JS. Applied logistic regression. New York: Wiley; 1989.

34. Gill TM, Gahbauer EA, Han L, Allore HG. Trajectories of disability in the last year of life. N Engl J Med. 2010;362:117380. http://dx.doi.org/10.1056/NEJMoa0909087.

35. Clay FJ, Newstead SV, Watson WL, Ozanne-Smith J, McClure RJ. Bio-psychosocial determinants of time lost from work following non life threatening acute orthopaedic trauma. BMC Musculoskelet Disord. 2010;11:6. http://dx.doi. org/10.1186/1471-2474-11-6.

36. MacKenzie EJ, Bosse MJ, Kellam JF, Pollak AN, Webb LX, Swiontkowski MF, et al. Early predictors of long-term work 
disability after major limb trauma. J Trauma. 2006;61:688-94. http://dx.doi.org/10.1097/01.ta.0000195985.56153.68.

37. MacKenzie EJ, Cushing BM, Jurkovich GJ, Morris JA, Jr., Burgess AR, deLateur BJ, et al. Physical impairment and functional outcomes six months after severe lower extremity fractures. J Trauma. 1993;34:528-39. http://dx.doi. org/10.1097/00005373-199304000-00009.

38. MacKenzie EJ, Morris JA, Jr., Jurkovich GJ, Yasui Y, Cushing $\mathrm{BM}$, Burgess AR, et al. Return to work following injury: the role of economic, social, and job-related factors. Am J Public Health. 1998;88:1630-7. http://dx.doi.org/10.2105/ AJPH.88.11.1630.

39. MacKenzie EJ, Shapiro S, Smith RT, Siegel JH, Moody M, Pitt A. Factors influencing return to work following hospitalization for traumatic injury. Am J Public Health. 1987;77:329-34. http://dx.doi.org/10.2105/AJPH.77.3.329.

40. Young AE. Return to work following disabling occupational injury--facilitators of employment continuation. Scand J Work Environ Health. 2010;36:473-83. http://dx.doi.org/10.5271/ sjweh.2986.

41. Clay FJ, Newstead S, McClure R. Determinants of time lost from work following acute non life threatening orthopaedic trauma. Injury. 2010;41:51-5. http://dx.doi.org/10.1016/j. injury.2010.01.074.

42. Baldwin ML, Johnson WG, Butler RJ. The error of using returns-to-work to measure the outcomes of health care. Am J Ind Med. 1996;29:632-41. http://dx.doi. org/10.1002/(SICI)1097-0274(199606)29:6<632::AIDAJIM7>3.0.CO;2-L.

43. Koehoorn M, Xu F, Village J, Trask C, Teschke K. Back injury trajectories in heavy industries: defining outcomes for epidemiological research. J Occup Environ Med. 2010;52:90812. http://dx.doi.org/10.1097/JOM.0b013e3181f02806.

44. Seland K, Cherry N, Beach J. A study of factors influencing return to work after wrist or ankle fractures. Am J Ind Med. 2006;49:197-203. http://dx.doi.org/10.1002/ajim.20258.
45. Nagin DS, Tremblay RE. Developmental trajectory groups: fact or a useful statistical fiction? Criminology. 2005;43:873904. http://dx.doi.org/10.1111/j.1745-9125.2005.00026.x.

46. Rusli BN, Edimansyah BA, Naing L. Working conditions, self-perceived stress, anxiety, depression and quality of life: a structural equation modelling approach. BMC Public Health. 2008;8:48. http://dx.doi.org/10.1186/1471-2458-8-48.

47. Jang Y, Wang YH, Wang JD. Return to work after spinal cord injury in Taiwan: the contribution of functional independence. Arch Phys Med Rehabil. 2005;86:681-6. http://dx.doi. org/10.1016/j.apmr.2004.10.025.

48. Tate DG. Workers' disability and return to work. Am J Phys Med Rehabil. 1992;71:92-6. http://dx.doi.org/10.1097/00002060199204000-00006.

49. Meerding WJ, Looman CW, Essink-Bot ML, Toet H, Mulder S, van Beeck EF. Distribution and determinants of health and work status in a comprehensive population of injury patients. J Trauma. 2004;56:150-61. http://dx.doi.org/10.1097/01. TA.0000062969.65847.8B.

50. Wasiak R, Young AE, Roessler RT, McPherson KM, van Poppel MN, Anema JR. Measuring return to work. J Occup Rehabil. 2007;17:766-81. http://dx.doi.org/10.1007/s10926007-9101-4.

51. Escorpizo R, Ekholm J, Gmunder HP, Cieza A, Kostanjsek N, Stucki G. Developing a Core Set to describe functioning in vocational rehabilitation using the international classification of functioning, disability, and health (ICF). J Occup Rehabil. 2010;20:502-11. http://dx.doi.org/10.1007/s10926-0109241-9.

52. Nilsing E, Soderberg E, Normelli H, Oberg B. Description of functioning in sickness certificates. Scand J Public Health. 2011;39:508-16. http://dx.doi. org/10.1177/1403494811399954.

Received for publication: 3 October 2011 